\title{
Aquaporins in Renal Diseases
}

\author{
Jinzhao He and Baoxue Yang *
}

State Key Laboratory of Natural and Biomimetic Drugs, Department of Pharmacology,

School of Basic Medical Sciences, Peking University, Beijing 100038, China; 18200288030@163.com

* Correspondence: baoxue@bjmu.edu.cn; Tel.: +86-10-82805622

Received: 25 December 2018; Accepted: 14 January 2019; Published: 16 January 2019

\begin{abstract}
Aquaporins (AQPs) are a family of highly selective transmembrane channels that mainly transport water across the cell and some facilitate low-molecular-weight solutes. Eight AQPs, including AQP1, AQP2, AQP3, AQP4, AQP5, AQP6, AQP7, and AQP11, are expressed in different segments and various cells in the kidney to maintain normal urine concentration function. AQP2 is critical in regulating urine concentrating ability. The expression and function of AQP2 are regulated by a series of transcriptional factors and post-transcriptional phosphorylation, ubiquitination, and glycosylation. Mutation or functional deficiency of AQP2 leads to severe nephrogenic diabetes insipidus. Studies with animal models show AQPs are related to acute kidney injury and various chronic kidney diseases, such as diabetic nephropathy, polycystic kidney disease, and renal cell carcinoma. Experimental data suggest ideal prospects for AQPs as biomarkers and therapeutic targets in clinic. This review article mainly focuses on recent advances in studying AQPs in renal diseases.
\end{abstract}

Keywords: aquaporin; vasopressin; nephrogenic diabetes insipidus; acute kidney injury; diabetic nephropathy; polycystic kidney disease; renal cell carcinoma

\section{Introduction}

Aquaporins (AQPs) are a family of highly selective transmembrane channels that mainly transport water across the cell and some facilitate low-molecular-weight solutes. AQPs consist of 13 members (AQP0-AQP12) in mammals and are widely distributed in various tissues and organs. According to their primary structure, they have been classified into three subfamilies. Water-selective AQPs include AQP0, AQP1, AQP2, AQP4, AQP5, AQP6, and AQP8, which are also known as orthodox aquaporins. Aquaglyceroporins, including AQP3, AQP7, AQP9, and AQP10, are permeable to water and some small uncharged solutes, such as glycerol and urea [1,2]. AQP3 AQP8, and AQP9 have been demonstrated to transport hydrogen peroxide $\left(\mathrm{H}_{2} \mathrm{O}_{2}\right)$ in mammalian cells $[3,4]$. The third subfamily named superaquaporins, including AQP11 and AQP12 [5], has low homology at its amino acid level with other classical AQPs. Due to a wide spectrum of pathophysiological function in balancing water homeostasis, modulating intracellular signaling, and regulating cell proliferation and oxidative stress response, AQPs have been proven to participate in renal diseases, dermatosis, bowel disease, and cancer [3,6-8]. This review article mainly focuses on the effect of AQPs in kidney diseases.

\section{Expression of Physiological Function of AQPs in the Kidney}

In the kidney, eight AQPs, including AQP1, AQP2, AQP3, AQP4, AQP5, AQP6, AQP7, and AQP11, are expressed in different segments and various cells to maintain normal urine concentration function, tissue development and substance metabolism [9,10] (Figure 1). 


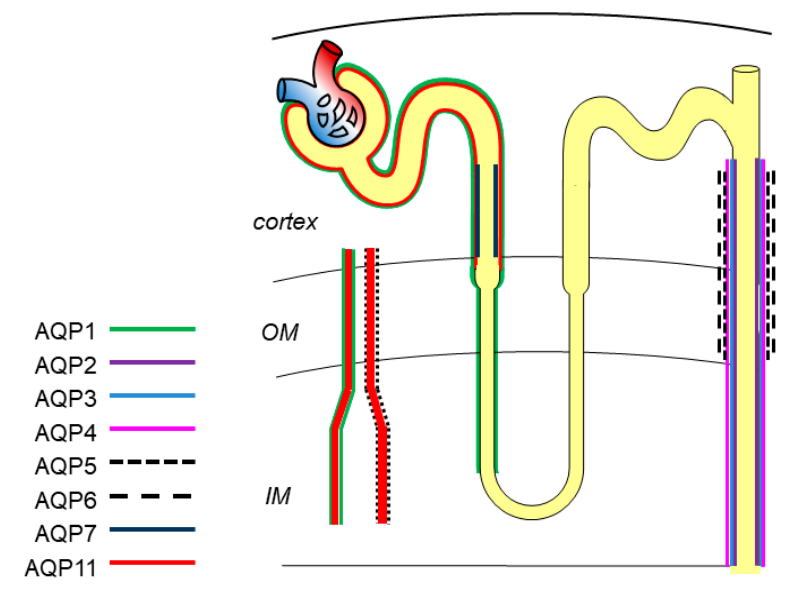

Figure 1. Expression localization of AQPs in kidney. AQP1 is located in proximal tubule, descending thin limbs of Henle, and vasa recta; AQP2, AQP3, AQP4, AQP5 and AQP6 are in the collecting duct; AQP7 and AQP11 are expressed in proximal tubule.

AQP1 is the first discovered water channel, and is located in the apical and basolateral plasma membrane of the proximal tubule, descending thin limbs of Henle, and descending vasa recta to mediate water reabsorption [11]. AQP1 is a highly selective water-permeable channel. Mice defective with AQP1 exhibit polyuria, indicating its key role in the formation of hypertonicity $[12,13]$.

AQP2 is one of the most important channel proteins involved in regulating urine concentration, and is located at the apical membrane of principal cells in the collecting duct [14]. The water reabsorption function of AQP2 is mainly regulated by arginine vasopressin (AVP) via increasing intracellular production of cyclic adenosine monophosphatase (cAMP) and further phosphorylation of AQP2 at Ser256 and Ser269 to stimulate the intracellular trafficking of AQP2 to the plasma membrane [15-17] (Figure 2). Besides AVP, researchers have demonstrated that activation of bile acid receptor TGR5 and hydrogen sulfide $\left(\mathrm{H}_{2} \mathrm{~S}\right)$ stimulates the expression of AQP2 via cAMP-protein kinase A (PKA) signaling pathway and attenuates the defection of urinary concentration in mice $[18,19]$. In fact, AQP2 expression, phosphorylation, and trafficking are not only activated by canonical AVP/cAMP/PKA signaling but also other signaling. Erlotinib, an epidermal growth factor receptor (EGFR) inhibitor, has been reported to enhance AQP2 accumulation in plasma membrane and water reabsorption through increasing phosphorylation of AQP2 at Ser-256 and Ser-269 and reducing endocytosis of AQP2 without affecting classic PKA signaling [20]. Administration of Wnt5a alleviated decreased urine osmolality and upregulation of AQP2 via activation of calcium/calmodulin/calcineurin signaling [21]. Additionally, the expression of AQP2 can be regulated by several transcription factors, such as AP-1, NF- $\mathrm{BB}$, and NFAT [22]. cAMP-responsive element binding protein (CREB) has been recognized as a major regulator of AQP2 expression. However, recent evidence identified that $\mathrm{C} / \mathrm{EBP} \beta$ is pertinent to transcriptional regulation of $A Q P 2$ and the relationship between CREB and AQP2 is indirect [23]. Notably, normal expression of AQP2 in apical plasma membrane plays a critically determinant role in renal urine concentration and body water balance. Deletion or mutation of the AQP2 gene causes severe water disorders and triggers the initiation of nephrogenic diabetes insipidus (NDI). Urinary excretion of AQP2 has been recognized as a useful marker for diagnosis of renal diseases [24]. 


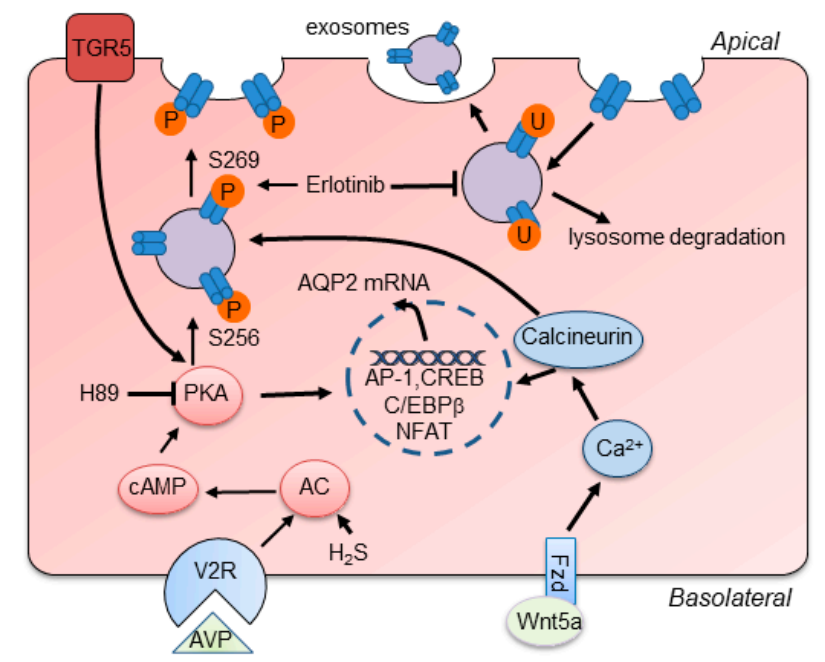

Figure 2. Schematic summary of main regulatory mechanisms of AQP2. AVP binding to V2R stimulates the activation of canonical cAMP/PKA signaling and increases the expression and phosphorylation of AQP2 at S256 and S269, leading to the apical membrane trafficking of AQP2. Activation of TGR5 increases the activation of PKA to induce the expression of AQP2. $\mathrm{H}_{2} \mathrm{~S}$ increases AQP2 expression via enhancing the activation of cAMP/PKA signaling. Besides, Wnt5a binds to Fzd receptors and increases the level of intracellular calcium, which stimulates calcineurin and increases the expression and phosphorylation of AQP2. Erlotinib promotes AQP2 expression in the apical membrane by increasing the phosphorylation of AQP2 and reducing its endocytosis and degradation. The translocation of AP-1, $\mathrm{CREB}, \mathrm{C} / \mathrm{EBP} \beta$, and NFAT into the nucleus regulates the expression of AQP2.

AQP3 is constitutively located in the basolateral membrane of principle cells in the cortex and outer medullar collecting duct and is regulated by thirst, AVP, and aldosterone. AQP4 is mostly distributed in the basolateral membrane of principle cells of the medullary segment of the collecting duct. Protein kinase $C$ and dopamine rather than AVP affect phosphorylation of AQP4 to regulate water permeability. AQP3 and AQP4 could export water entering cytoplasm via AQP2. Of note, AQP3 also facilitates glycerol and hydrogen peroxide transport through the cell membrane, which regulates a series of intracellular signaling and affects cellular functions, such as cell proliferation, apoptosis and migration [6]. AQP3-null mice showed NDI-like phenotype, while the absence of AQP4 only presented mild urinary concentration defect. However, the double knockout mice of AQP3/AQP4 have a greater impairment of urinary function than AQP3-null mice [25,26], which may be due to their similar localization and water permeability in the urinary tract.

A few years ago, scientists firstly reported that AQP5 is located in type B intercalated cells of collecting ducts [27]. AQP6 is localized in the intracellular vesicles of intercalated cells and colocalized with $\mathrm{H}^{+}$-ATPase [28]. AQP6 hardly transports water from the membrane unless at a low $\mathrm{pH}$ value. The function of AQP5 and AQP6 in the kidney is still not clear.

AQP7 is expressed in the brush border of the S3 segment of the proximal tubule, and shows great effect on metabolism by regulating the transportation of glycerol. Defective AQP7 expression has little effect on water permeability of proximal tubules, but is associated with significant metabolism disorders, like obesity and insulin resistance [29].

AQP11 is uniquely localized in the membrane of endoplasmic reticulum (ER) of proximal tubular cells. The transport function of AQP11 is controversial regarding whether it transports water and glycerol or only glycerol [30]. AQP11 knockout mice develop uremia due to the renal cysts derived from the proximal tubule.

Nowadays, the pathophysiologic functions of AQPs in renal-specific cell types and liquid homeostasis have been deeply studied to provide the therapeutic targets. The data showed that AQPs might be an ideal biomarker for renal diseases [31-33]. This review article focuses on the pathophysiological effect of AQPs in renal diseases and potential therapeutic targets of AQPs. 


\section{Functional Deficiency of AQP2 Causes NDI}

NDI is a rare disease characterized by polyuria and polydipsia. Patients with NDI produce around $12 \mathrm{~L}$ of urine per $24 \mathrm{~h}$. Congenital NDI is caused by the mutation of the AVP receptor 2 (about $90 \%$ ) or AQP2 (about 10\%) gene [34]. AQP2 mutations in NDI patients are autosomal recessive inheritance. In patients, the urinary AQP2 excretion could be used to evaluate the mutation of AVPR2 [35]. Acquired NDI results from chemical substances, electrolyte abnormalities, and obstructive uropathy $[14,36]$. Lithium-induced NDI is the most common cause among patients, due to the wide use of lithium for psychiatric disorders, which affects AQP2 function. So far, the treatment for NDI in clinic mainly includes dietary modulation, thiazide diuretics, amiloride, and prostaglandin synthesis inhibitors [37]. However, these therapies only ameliorate the symptoms of NDI without radical cure. The alteration of AQP2 expression is the predominant cause of heritable and acquired NDI. Thus, strategies to increase the functional accumulation of AQP2 in the apical membrane might be useful in treating NDI, such as AVP analogues, prostaglandin receptor agonists, and cGMP phosphodiesterase inhibitors [34].

AQP2 functional deficiency causing NDI was determined by several genetic mouse models [38-40]. The AQP2-T126M mutant protein of AQP2 ${ }^{\mathrm{T} 126 \mathrm{M} /-}$ mice kidney collecting duct epithelial cells was distributed in the endoplasmic reticulum rather than in the apical membrane where the wild-type AQP2 protein was located (Figure 3A). Meanwhile, less than $10 \%$ of collecting duct epithelial cells presented normal localization of AQP2 (Figure 3A, white arrow). Immunoblot analysis of wild-type and $\mathrm{AQP2}{ }^{\mathrm{T} 126 \mathrm{M} /-}$ mice whole-kidney homogenates showed that the core-glycosylated form of AQP2-T126M, a band at $\sim 31 \mathrm{kDa}$ rather than wild-type AQP2, two bands around 34-40 kDa and $29 \mathrm{kDa}$, was shown in AQP2 ${ }^{\mathrm{T} 126 \mathrm{M} /-}$ mice (Figure 3B). After treatment of heat shock protein 90 (Hsp90) inhibitor 17-allylamino-17-demethoxygeldanamycin (17-AAG), the immunoblot analysis of AQP2 showed the restoration of glycosylated and nonglycosylated bands and the lower level of $\sim 31 \mathrm{kDa}$ and $\sim 23 \mathrm{kDa}$ bands, which implied the partial correction of AQP2 expression in AQP2 ${ }^{\mathrm{T} 126 \mathrm{M} /-}$ mice. The results showed that 17-AAG partially restored defective AQP2 cellular processing and increased urine osmolality in AQP2 mutation mice by $>300$ mosmol but had no effect in AQP2-null mice. (Figure 3D). This study not only generated an adult NDI animal model that mimics NDI patients with AQP2 mutation, but also used 17-AAG for partially correcting the expression of AQP2 to attenuate the urinary concentration defect. These data suggest a novel therapeutic way to treat NDI and show a promising clinic prospect for 17-AAG and other small molecules. Of note, regulating AQP2 protein expression has been an effective way to elucidate the underlying mechanisms of NDI and explore the

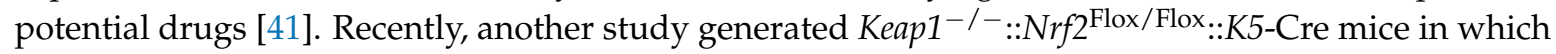
constitutive Nrf2 activation caused NDI by reducing AQP2 expression [42].

In hypokalemia-induced NDI, autophagic degradation led to the decreasing expression of AQP2 in the early stage [43]. Based on proteomic and bioinformatic analysis, researchers revealed that the degradation of AQP2 plays a pivotal role in the onset of hypercalcemic-induced NDI [44]. Lithium-induced NDI has been a common animal model for exploring NDI-related mechanisms and potential drugs. Sustained intake of lithium caused the downregulation of AQP2 and AQP3 protein levels and impaired urinary concentration ability. Utilizing this model, scientists have provided evidences that activation of TGR5 and production of $\mathrm{H}_{2} \mathrm{~S}$ attenuated the symptoms of NDI [18,19]. In the other study, researchers found that pharmacological blockade or genetic deletion of P2Y12 blunted the reduction of AQP2 and polyuria induced by lithium. Therefore, these data indicate that pharmacological activation of TGR5, $\mathrm{H}_{2} \mathrm{~S}$, and inhibition of P2Y12 show potential to treat NDI. 

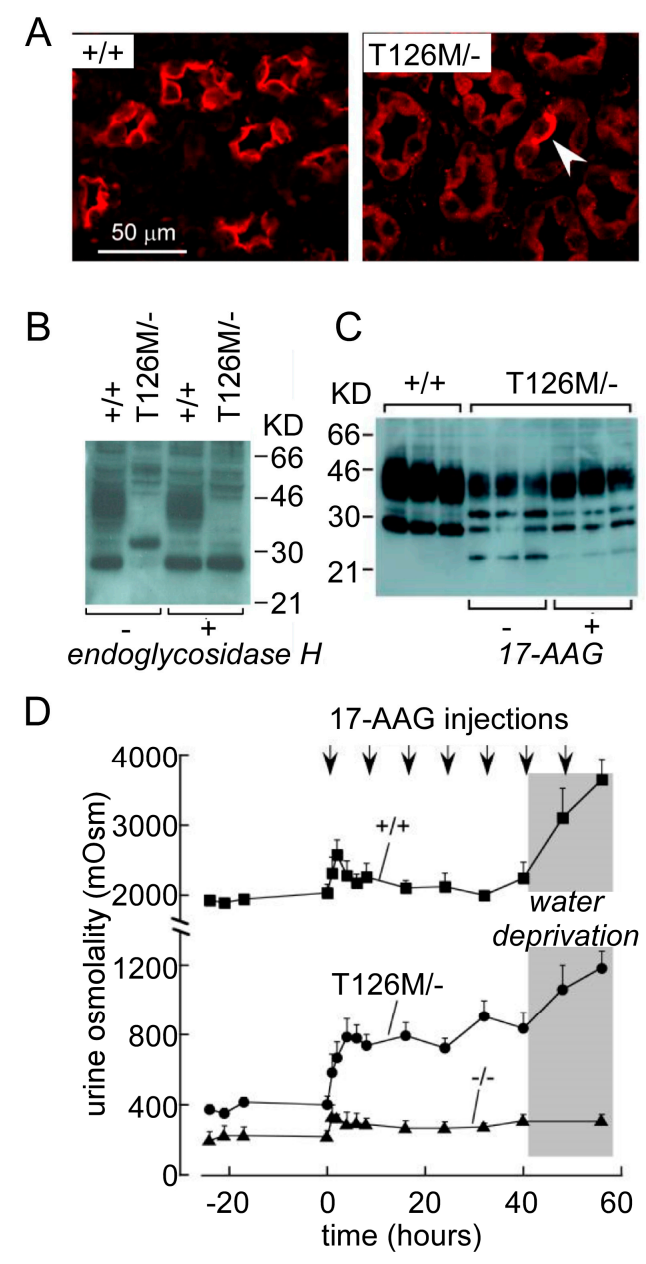

Figure 3. NDI caused by AQP2 mutation. (A) The immunofluorescence of AQP2 in kidneys of wild-type (left) and inducible AQP2 ${ }^{\mathrm{T} 126 \mathrm{M} /-}$ mice (right). (B) Immunoblot of AQP2 from wild-type and inducible AQP2 ${ }^{\mathrm{T} 126 \mathrm{M} /-}$ mice. (C) AQP2 protein immunoblot of kidney homogenates from wild-type and $\mathrm{AQP} 2^{\mathrm{T} 126 \mathrm{M} /-}$ mice treated with or without Hsp90 inhibitor 17-AAG. (D) Urine osmolality in wild-type, AQP2 knockout, and inducible AQP2 ${ }^{\mathrm{T} 126 \mathrm{M} /-}$ mice given free access to food and water before and after 17-AAG treatment. The block, solid ball, and triangle represent wild-type mice, $\mathrm{AQP} 2^{\mathrm{T} 126 \mathrm{M} /-}$ mice, and AQP2 ${ }^{-/-}$mice, respectively (adapted from Ref [38]).

In the past few years, PKA signaling has been identified as a traditional pathway for exploring underlying mechanisms and therapeutic targets of NDI. Deletion or inhibition of adenylate cyclase 6 or glycogen synthase kinase $3 \beta$ (GSK3 $\beta$ ) decreased the level of cAMP and reduced expression of AQP2 to elicit NDI $[45,46]$. Fumiaki et al. have reported that low-molecular-weight compound 3,3'-Diamino-4,4'-dihydroxydiphenylmethane (FMP-API-1) and its derivatives stimulated PKA and obviously increased AQP2 activity to protect mice from NDI [47]. Besides, prostaglandin E2 receptor 4 and (pro)renin receptor play important roles in regulation of AQP2 expression and urine concentrating capability via activating the cAMP/PKA pathway $[48,49]$. However, strategies targeting the cAMP/PKA pathway have shown severe side effects and poor outcomes. Alternative novel therapies have been sought in recent years, such as EGFR inhibition and Wnt5a administration. Statins, as a kind of safe and effective lipid-lowering drug, show potential to remedy NDI through increasing the mRNA and proteins of AQP2 [50].

Furthermore, extracellular matrix (ECM) affects the expression of AQP2 and might open new venues for treatment of NDI. Integrin-linked kinase (ILK) as a scaffold protein that links ECM with intracellular signaling increased the expression AQP2 by activating ILK/GSK3 $\beta / N F A T$ axis and knockdown of ILK displayed a symptom of NDI [51]. 


\section{AQPs in Acute Kidney Injury}

Acute kidney injury (AKI) is a worldwide syndrome with high morbidity and mortality characterized by rapidly declined glomerular filtration. The occurrence of AKI is approximately 13.3 million people per year and $36 \%$ of them are required to take renal replacement therapy. AKI can be elicited by prerenal factors (almost 60\%; heart failure, sepsis, drugs), intrarenal factors (approximately 35\%; nephrotoxic substances induced acute tubule necrosis, interstitial nephritis, intrarenal deposition), and postrenal factors (almost 5\%; tumor, clot, neurogenic bladder) [52].

Renal ischemia/reperfusion (I/R) injury is a common cause of AKI. Several reports have shown that the expression of AQPs is closely related with I/R-induced AKI [53]. The protein expression of AQP1, AQP2, and AQP3 has been shown significantly decreased which could account for the defect in urinary concentration in I/R mice [54]. Urinary exosomal release of AQP1 and AQP2 was reduced at the stage of AKI and in bilateral and unilateral I/R rats [53]. Lack of AQP1 makes mice more sensitive to I/R kidney injury. A study reported that endotoxemia-induced AKI is more severe in AQP1 knockout mice, implying the importance of AQP1 channel [55].

Lei et al. proved that deletion of $A Q P 3$ aggravated the kidney injury by increased apoptosis and inhibited MAPK signaling in I/R mice [56]. The results showed the blood urea nitrogen (BUN) and creatinine levels were significantly elevated after I/ $\mathrm{R}$ in $\mathrm{AQP3}{ }^{-/-}$mice (Figure $4 \mathrm{~A}, \mathrm{~B}$ ). The SOD activity and MDA level were obviously altered in $\mathrm{AQP3}^{-/-}$mice but not in wild-type mice after I/R (Figure 4C,D), which was in accordance with injured renal morphology and increased apoptosis level. Hematoxylin-eosin staining showed significant tubular morphological damage in AQP3 ${ }^{-/-}$ kidneys with I/R, but not in wild-type kidneys (Figure 4E). For underlying mechanisms, Western blot analysis showed the activation of pro-apoptotic protein Bax and inhibition of antiapoptotic protein $\mathrm{Bcl}-2$ and upregulated expression level of cleaved caspase-3 and p-p53, indicating the increased level of apoptosis in AQP3 ${ }^{-/-}$mice with I/R (Figure $4 \mathrm{~F}$, left panel). AQP3 ${ }^{-/-}$kidneys showed downregulated p38/ERK/JNK MAPK signaling, which was reversed by I/R. These data provide the evidence that AQP3-mediated apoptosis and MAPK signaling play pivotal roles in I/R, which might be an effective target in future. Global analysis of differential gene expression in desert-adapted animals showed that the expression of AQP4 is significantly reduced in acute dehydration, which might play a role in water handling to prevent kidney injury [57]. In the cisplatin-induced kidney injury animal model, the level of AQP1-3 decreased and L-carnitine ameliorated the urinary concentration defect by increasing AQP2 expression [58].

Another study has reported that downregulation of AQP2 expression in lipopolysaccharide-induced AKI participated in urinary concentration defect in sepsis [59]. Interestingly, reducing the activation of NF-KB signaling ameliorated the downregulation of AQP2 protein and sepsis-induced acute renal failure $[60,61]$. Using a renal transplantation animal model, the data showed that the reduced AQP2 expression in phase of acute graft rejection could be blunted by administration of cyclosporine $[62,63]$. Thus, the decreased level of AQP2 partially accounts for the mechanism of acute renal disease, which suggests targeting AQP2 as a new therapeutic way for AKI. In addition, AQP11 rs2276415 variant renders diabetic patients with higher risk for AKI $[64,65]$. To some extent, restoration or correction of AQPs may protect patients from AKI. 
A

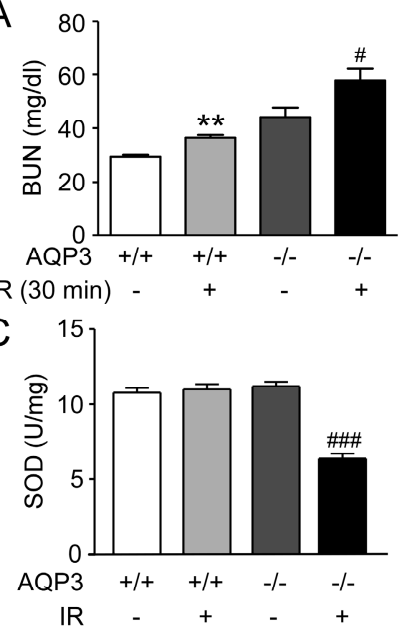

B

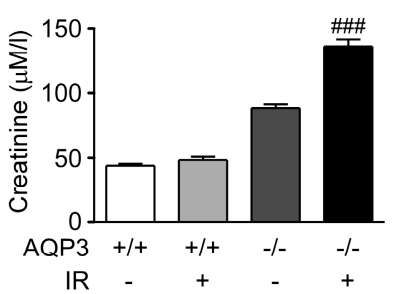

D

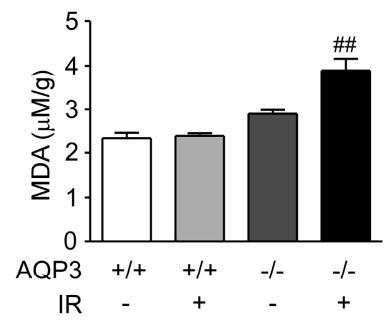

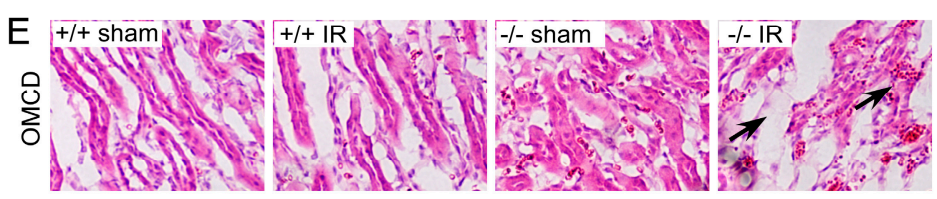

$\mathrm{F}$
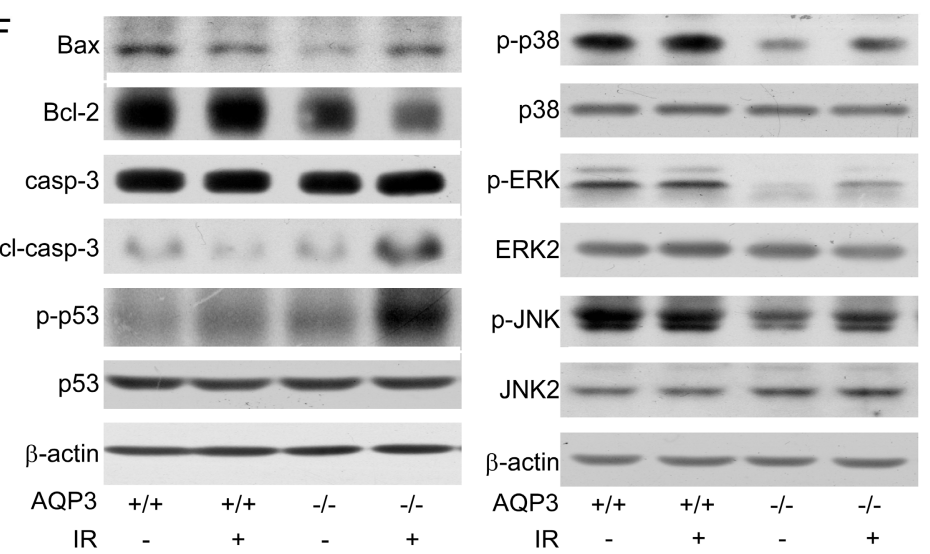

Figure 4. AQP3 deficiency aggravates IR injury. (A) Serum BUN level in wild-type and $\mathrm{AQP}^{-/-}$mice after reperfusion following $30 \mathrm{~min}$ ischemia. (B) Serum creatinine level in wild-type and AQP3-/mice after reperfusion following $30 \mathrm{~min}$ ischemia. (C) The activity of SOD in renal tissue. (D) The level of MDA in renal tissue. (E) Representative outer medullary collecting duct (OMCD) images of H\&E staining of wild-type and AQP3 ${ }^{-/}$kidneys after sham surgery or I/R. Black arrow represents dilated collecting ducts. (F) Different protein expression level of kidneys after reperfusion was detected by Western blot (adapted from Ref [56]).

\section{AQPs in Diabetic Nephropathy}

Diabetic nephropathy (DN) is one of the most common complications of diabetes mellitus (DM), which occurs in one-third of diabetic patients [66]. DN is a slowly progressive disease with impaired renal function and fluid balance disorder, and is the leading cause of end-stage renal disease (ESRD) in adults [67]. As polyuria is an early sign of DN, the role of AQPs in the pathophysiology of DN has been studied in recent years [33].

A growing body of evidence showed that the expression of AQPs was dysregulated in DN patients. AQP5 is obviously increased in the kidney tissue of DN patients and urine AQP2 and AQP5 have been identified as potential novel biomarkers of diabetic nephropathy with sensitivity, early appearance, and low invasiveness features [68-70]. A community-based cohort study involving 620 participants with chronic kidney disease (CKD) firstly revealed that AQP11 rs2276415 variant is associated with CKD progression [69]. Similarly, Choma et al. reported AQP11 rs2276415 variant as a genetic factor 
predisposing type 2 diabetic patients to a greater risk for the development of CKD [64]. Early detection of urine exosomes and genetic screening of AQPs might assist clinical diagnosis and treatment of DN.

\section{AQPs in Polycystic Kidney Disease}

Autosomal dominant polycystic kidney disease (ADPKD) is a common hereditary disease, affecting 1/1000-1/400 individuals worldwide [71]. The mutations of $p k d 1(85 \%)$ and $p k d 2(15 \%)$, which encode polycystin1 (PC1) and polycystin2 (PC2) respectively, cause the formation and enlargement of renal cysts in ADPKD [72]. Fifty percent of patients until the sixth decade of life reach ESRD with extrarenal manifestations, such as liver cysts, cerebral aneurysms, and cardiovascular disorders [73]. ADPKD is characterized by bilateral multiple fluid-filled cysts, damaged functional renal parenchymal, and reduced renal function, and is manifested with excessive proliferation of renal epithelium, secretion of cystic fluid and interstitial fibrosis [74]. Yet, only type-2 AVP receptor antagonist tolvaptan has been approved by FDA for treating ADPKD [75].

The pathophysiological mechanisms of ADPKD involves the abnormal intracellular calcium concentration and increased cAMP level, which activate repair signaling, including MAPK/ERK, PI3K/Akt, mTOR, Wnt/ $\beta$-catenin, and so forth [76,77]. Although there is still a lack of satisfactory therapeutic drugs and the underlying mechanisms are not fully understood, AQPs have shown pivotal roles in the progression of ADPKD.

The first evidence of AQPs playing a role in ADPKD came from human samples [78]. Our group has reported that AQP1 mediated the inhibition of renal cyst development by restraining Wnt/ $\beta$-catenin signaling in an orthologous ADPKD mice model [79] (Figure 5). The data presented that overexpressing AQP1 inhibited cyst growth in MDCK cyst model (Figure 5A). Contrarily, deletion of $A Q P 1$ promoted cyst development in embryonic kidney and PKD mice (Figure 5B,C). In immunoprecipitation analysis, AQP1 was shown to interact with $\beta$-catenin, GSK3 $\beta$, LRP6, and Axin1 (Figure 5D). Thus, the presence of AQP1 might directly cause the stability of destruction complex increased and promote the phosphorylation and degradation of $\beta$-catenin (Figure 5D), which suggests loss of AQP1 increases $\beta$-catenin accumulation and translocation into the nucleus to promote the transcription of Wnt target genes. AQP1 has great possibility to inhibit Wnt signaling and shows potential to retard the progression of renal cysts in clinic.

Overexpression and mislocalization of AQP2 in the cytoplasm of collecting cells were observed in HIF- $1 \alpha$ mutant mice, with renal cyst formation and urinary concentration defect [80]. In one study, steviol slowed cyst growth by reducing AQP2 expression and promoting AQP2 degradation in vitro [81]. This evidence shows potential therapeutic exploitation avenues for AQPs in ADPKD.

In addition, deletion of Aqp 11 caused proximal tubule cyst formation in the kidney, which results from the defective trafficking of PC1 [82]. AQP11-null mice have been an ideal model for studying proximal tubular cyst formation in ADPKD [83]. Therefore, the mutation of AQP11 established a novel tool for studying renal cyst diseases. 


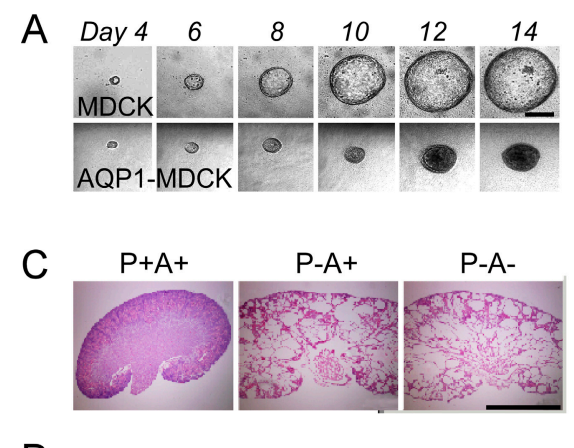

D
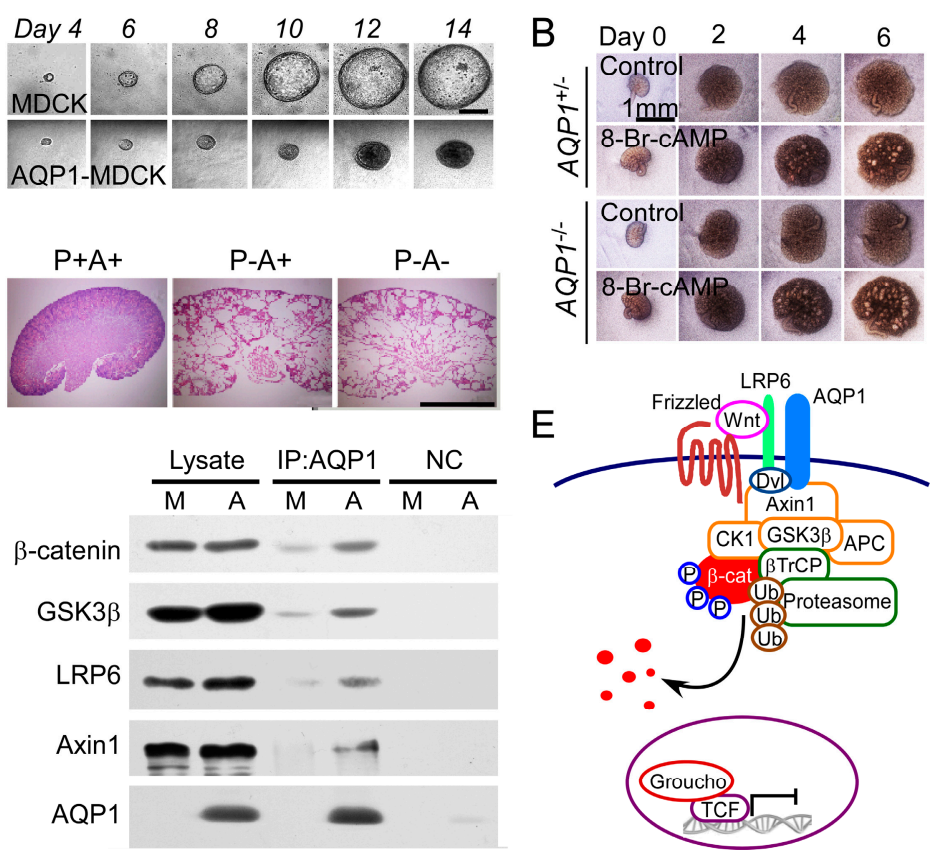

Figure 5. AQP1 retards renal cyst development. (A) Representative images of MDCK and AQP1-MDCK cyst from day 4 to day 14 . (B) Representative images of $\mathrm{AQP1} 1^{+/-}$and $\mathrm{AQP1} 1^{-/-}$embryonic kidney cyst from day 0 to day 6. (C) Representative images of wild-type, PKD, and AQP1 ${ }^{-/-}$PKD kidneys. (D) Coimmunoprecipitation with anti-AQP1 showing the protein AQP1 interaction with $\beta$-catenin, GSK3 $\beta$, LRP6, and Axin1 in AQP1-MDCK cells. M and A indicate MDCK cells and AQP1-MDCK cells, respectively. (E) Schematic of AQP1 regulating $\beta$-catenin (adapted from Ref [79]).

\section{AQP1 in Renal Cell Carcinoma}

With the development of imaging technologies, the incidence of renal carcinoma increased in recent years. Renal cell carcinoma (RCC) is the most common neoplasm in the kidney and accounts for almost 3\% 4\% of adult malignant tumors [84]. About 30\% of patients are unsuitable to be cured by surgical resection due to tumor metastasis [85]. Therefore, early diagnosis is pretty essential for treatment of RCC. A growing body of studies have identified that urine level of AQP1 is a sensitive, specific, reliable diagnostic biomarker for clear cell and papillary RCC [86-88]. Although the role of AQPs in the initiation and development of neoplasm has not been reported, cancer shares a lot in common with ADPKD, which sheds light on further research in renal cancer [89].

\section{AQPs in Renal Fibrosis}

Renal fibrosis is the common endpoint event of various CKDs and the extent of fibrosis indicates the residual renal function [90]. Fibrosis represents a series of dynamic processes involving imbalance between production and degradation of ECM, epithelial-to-mesenchymal transition (EMT), immune cell infiltration, and fibroblast activation [91]. Intervention in the progression of renal fibrosis highlights a promising therapeutic target for CKD. Loss of AQP1 was found in the unilateral ureteral obstruction (UUO) mice kidney, which could be reversed by EMT suppression, indicating AQP1 was involved in the process of EMT [92]. An in vitro study utilizing human proximal tubular epithelial cells showed the expression of AQP1 decreased in the model of aristolochic acid 1 (AA-1)-induced EMT and was regulated by ERK1/2 signaling, which implied that AQP1 might be a novel target for EMT [93].

In UUO animal models, it has been proven that the abundance of AQP2 was reduced partly leading to urinary concentrating defect [94]. Cholecalciferol cholesterol emulsion has been demonstrated to inhibit renal fibrosis through increasing AQP2 and decreasing AQP4 protein expression in UUO animal models [95]. Moreover, aliskiren restored the protein level of AQP2 by inhibiting inflammasome to exert its protective effect in the obstructed kidneys [94]. In future 
studies, inhibitors or drugs regulating the expression of AQPs may provide a new perspective for preventing fibrosis.

\section{Other Diseases}

In addition, analysis of three patients with autoimmune diseases showed autoantibodies targeting AQP2 or its upstream molecules caused tubulointerstitial nephritis [96]. Urinary increased excretion of AQP2 was mainly responsible for polyuria in patients with pyelonephritis and IgA nephropathy, suggesting AQP2 may be a treatment target for those diseases [97,98].

The reduced expression of AQP1, AQP2, and AQP4 was observed in mice with hydronephrosis [99]. Of note, although numerous studies have shown that the expression of AQPs was altered in renal diseases, the specific and direct role and function of AQPs, due to their permeability of water and other small molecules and regulation of intracellular signaling, require further study by the aid of AQPs knockout or overexpressing animal models.

\section{Future Perspectives}

An abundance of evidence has implied that AQPs are potential targets for a series of related disorders, such as NDI, ADPKD, edema, inflammatory disease and cancer [100]. However, the underlying mechanisms are not fully understood yet. In consideration of the permeability of AQPs, the effect of molecules crossing cell membranes depending on AQPs should be associated with the elucidation of their roles in renal diseases. Mice deficient in AQP1, AQP2, AQP3, and AQP4 exhibit diuresis. Restoration of these functional AQPs shows potential to treat NDI and inhibitors of these AQPs are predicted to be novel diuretics. The transportation of glycerol, $\mathrm{H}_{2} \mathrm{O}_{2}$ and other small molecules into cells might affect the intracellular signaling to regulate cellular proliferation, energy metabolism, and inflammation. Modulation of AQP-mediated small-molecule transport might be the drug target for AKI, PKD, renal fibrosis, and RCC. With clarification of AQP structure, computational methods have been used to screen AQP inhibitors for drug discovery. Because of the absence of gold-standard assays of AQP activity and the poor druggability of known small molecules, the development of AQP inhibitors progressed slowly [100]. So far, several compounds and pharmaceutical formulations have been proposed to modulate the function of AQPs and might provide new tools for studying related diseases [1]. Notwithstanding, the absence of effective AQP modulators hinders the development of therapeutic intervention and the translation from bench to bedside. In future studies, exploring highly selective, stable, and safe AQP inhibitors or activators will allow scientists to evaluate the physiological effects and therapeutic consequences.

Author Contributions: J.H. wrote the manuscript. B.Y. is the correspondence author and edited the manuscript. Both authors commented and approved the final manuscript.

Funding: This work was supported by National Natural Science Foundation of China grants 81620108029, 81261160507, 81330074, 81170632, and 81370783, and Beijing Natural Science Foundation grant 7172113, and the 111 Project.

Conflicts of Interest: The authors declare no competing financial interests.

\section{Abbreviations}

$\begin{array}{ll}\text { AQPs } & \text { Aquaporins } \\ \mathrm{H}_{2} \mathrm{O}_{2} & \text { Hydrogen peroxide } \\ \text { AVP } & \text { Arginine vasopressin } \\ \text { cAMP } & \text { Cyclic adenosine monophosphatase } \\ \text { PKA } & \text { Protein kinase A } \\ \mathrm{H}_{2} \mathrm{~S} & \text { Hydrogen sulfide } \\ \text { EGFR } & \text { Epidermal growth factor receptor } \\ \text { CREB } & \text { cAMP-responsive element binding protein } \\ \text { NDI } & \text { Nephrogenic diabetes insipidus }\end{array}$




$\begin{array}{ll}\text { ER } & \text { Endoplasmic reticulum } \\ \text { Hsp } & \text { Heat shock protein } 90 \\ \text { 17-AAG } & \text { 17-allylamino-17-demethoxygeldanamycin } \\ \text { GSK3 } \beta & \text { Glycogen synthase kinase } 3 \beta \\ \text { ECM } & \text { Extracellular matrix } \\ \text { ILK } & \text { Integrin-linked kinase } \\ \text { AKI } & \text { Acute kidney injury } \\ \text { I/R } & \text { Ischemia/reperfusion } \\ \text { BUN } & \text { Blood urea nitrogen } \\ \text { DN } & \text { Diabetic nephropathy } \\ \text { DM } & \text { Diabetes mellitus } \\ \text { ESRD } & \text { End-stage renal disease } \\ \text { CKD } & \text { Chronic kidney disease } \\ \text { ADPKD } & \text { Autosomal dominant polycystic kidney disease } \\ \text { PC1 } & \text { Polycystin 1 } \\ \text { PC2 } & \text { Polycystin 2 } \\ \text { RCC } & \text { Renal cell carcinoma } \\ \text { EMT } & \text { Epithelial-to-mesenchymal transition } \\ \text { UUO } & \text { Unilateral ureteral obstruction }\end{array}$

\section{References}

1. Soveral, G.; Casini, A. Aquaporin modulators: A patent review (2010-2015). Expert Opin. Ther. Pat. 2017, 27, 49-62. [CrossRef] [PubMed]

2. Geng, X.; Yang, B. Transport Characteristics of Aquaporins. Adv. Exp. Med. Biol. 2017, 969, 51-62.

3. Miller, E.W.; Dickinson, B.C.; Chang, C.J. Aquaporin-3 mediates hydrogen peroxide uptake to regulate downstream intracellular signaling. Proc. Natl. Acad. Sci. USA 2010, 107, 15681-15686. [CrossRef] [PubMed]

4. Watanabe, S.; Moniaga, C.S.; Nielsen, S.; Hara-Chikuma, M. Aquaporin-9 facilitates membrane transport of hydrogen peroxide in mammalian cells. Biochem. Biophys. Res. Commun. 2016, 471, 191-197. [CrossRef] [PubMed]

5. Ishibashi, K.; Hara, S.; Kondo, S. Aquaporin water channels in mammals. Clin. Exp. Nephrol. 2009, 13, 107-117. [CrossRef]

6. Hara-Chikuma, M.; Satooka, H.; Watanabe, S.; Honda, T.; Miyachi, Y.; Watanabe, T.; Verkman, A.S. Aquaporin-3-mediated hydrogen peroxide transport is required for NF-kappaB signalling in keratinocytes and development of psoriasis. Nat. Commun. 2015, 6, 7454. [CrossRef]

7. Chen, Y.; Jin, S.; Teng, X.; Hu, Z.; Zhang, Z.; Qiu, X.; Tian, D.; Wu, Y. Hydrogen Sulfide Attenuates LPS-Induced Acute Kidney Injury by Inhibiting Inflammation and Oxidative Stress. Oxid. Med. Cell. Longev. 2018, 2018. [CrossRef]

8. Vieceli, D.S.F.; Zambonin, L.; Fiorentini, D.; Rizzo, B.; Caliceti, C.; Landi, L.; Hrelia, S.; Prata, C. Specific aquaporins facilitate Nox-produced hydrogen peroxide transport through plasma membrane in leukaemia cells. Biochim. Biophys. Acta 2014, 1843, 806-814. [CrossRef]

9. Noda, Y.; Sohara, E.; Ohta, E.; Sasaki, S. Aquaporins in kidney pathophysiology. Nat. Rev. Nephrol. 2010, 6, 168-178. [CrossRef]

10. Li, Y.; Wang, W.; Jiang, T.; Yang, B. Aquaporins in Urinary System. Adv. Exp. Med. Biol. 2017, 969, 131-148.

11. Chou, C.L.; Knepper, M.A.; Hoek, A.N.; Brown, D.; Yang, B.; Ma, T.; Verkman, A.S. Reduced water permeability and altered ultrastructure in thin descending limb of Henle in aquaporin-1 null mice. J. Clin. Investig. 1999, 103, 491-496. [CrossRef]

12. Yang, B.; Ma, T.; Verkman, A.S. Erythrocyte water permeability and renal function in double knockout mice lacking aquaporin-1 and aquaporin-3. J. Biol. Chem. 2001, 276, 624-628. [CrossRef]

13. Verkman, A.S.; Yang, B. Aquaporin gene delivery to kidney. Kidney Int. 2002, 61, S120-S124. [CrossRef]

14. Ren, H.; Yang, B.; Molina, P.A.; Sands, J.M.; Klein, J.D. NSAIDs Alter Phosphorylated Forms of AQP2 in the Inner Medullary Tip. PLoS ONE 2015, 10, e141714. [CrossRef]

15. Kavanagh, C.; Uy, N.S. Nephrogenic Diabetes Insipidus. Pediatr. Clin. N. Am. 2019, 66, 227-234. [CrossRef] 
16. Ren, H.; Yang, B.; Ruiz, J.A.; Efe, O.; Ilori, T.O.; Sands, J.M.; Klein, J.D. Phosphatase inhibition increases AQP2 accumulation in the rat IMCD apical plasma membrane. Am. J. Physiol. Ren. Physiol. 2016, 311, F1189-F1197. [CrossRef]

17. Lei, L.; Huang, M.; Su, L.; Xie, D.; Mamuya, F.A.; Ham, O.; Tsuji, K.; Paunescu, T.G.; Yang, B.; Lu, H. Manganese promotes intracellular accumulation of AQP2 via modulating F-actin polymerization and reduces urinary concentration in mice. Am. J. Physiol. Ren. Physiol. 2018, 314, F306-F316. [CrossRef]

18. Li, S.; Qiu, M.; Kong, Y.; Zhao, X.; Choi, H.J.; Reich, M.; Bunkelman, B.H.; Liu, Q.; Hu, S.; Han, M.; et al. Bile Acid G Protein-Coupled Membrane Receptor TGR5 Modulates Aquaporin 2-Mediated Water Homeostasis. J. Am. Soc. Nephrol. 2018, 29, 2658-2670. [CrossRef]

19. Luo, R.; Hu, S.; Liu, Q.; Han, M.; Wang, F.; Qiu, M.; Li, S.; Li, X.; Yang, T.; Fu, X.; et al. Hydrogen sulfide upregulates renal AQP-2 protein expression and promotes urine concentration. FASEB J. 2018, 33, 469-483. [CrossRef]

20. Cheung, P.W.; Nomura, N.; Nair, A.V.; Pathomthongtaweechai, N.; Ueberdiek, L.; Lu, H.A.; Brown, D.; Bouley, R. EGF Receptor Inhibition by Erlotinib Increases Aquaporin 2-Mediated Renal Water Reabsorption. J. Am. Soc. Nephrol. 2016, 27, 3105-3116. [CrossRef]

21. Ando, F.; Sohara, E.; Morimoto, T.; Yui, N.; Nomura, N.; Kikuchi, E.; Takahashi, D.; Mori, T.; Vandewalle, A.; Rai, T.; et al. Wnt5a induces renal AQP2 expression by activating calcineurin signalling pathway. Nat. Commun. 2016, 7, 13636. [CrossRef]

22. Kortenoeven, M.L.; Trimpert, C.; van den Brand, M.; Li, Y.; Wetzels, J.F.; Deen, P.M. In mpkCCD cells, long-term regulation of aquaporin-2 by vasopressin occurs independent of protein kinase A and CREB but may involve EPAC. Am. J. Physiol. Ren. Physiol. 2012, 302, F1395-F1401. [CrossRef]

23. Jung, H.J.; Raghuram, V.; Lee, J.W.; Knepper, M.A. Genome-Wide Mapping of DNA Accessibility and Binding Sites for CREB and C/EBPbeta in Vasopressin-Sensitive Collecting Duct Cells. J. Am. Soc. Nephrol. 2018, 29, 1490-1500. [CrossRef]

24. Krais, A.M.; Andersen, C.; Eriksson, A.C.; Johnsson, E.; Nielsen, J.; Pagels, J.; Gudmundsson, A.; Lindh, C.H.; Wierzbicka, A. Excretion of Urinary Metabolites of the Phthalate Esters DEP and DEHP in 16 Volunteers after Inhalation and Dermal Exposure. Int. J. Environ. Res. Public Health 2018, 15. [CrossRef]

25. Ma, T.; Song, Y.; Yang, B.; Gillespie, A.; Carlson, E.J.; Epstein, C.J.; Verkman, A.S. Nephrogenic diabetes insipidus in mice lacking aquaporin-3 water channels. Proc. Natl. Acad. Sci. USA 2000, 97, 4386-4391. [CrossRef]

26. Kortenoeven, M.L.; Fenton, R.A. Renal aquaporins and water balance disorders. Biochim. Biophys. Acta 2014, 1840, 1533-1549. [CrossRef]

27. Procino, G.; Mastrofrancesco, L.; Sallustio, F.; Costantino, V.; Barbieri, C.; Pisani, F.; Schena, F.P.; Svelto, M.; Valenti, G. AQP5 is expressed in type-B intercalated cells in the collecting duct system of the rat, mouse and human kidney. Cell. Physiol. Biochem. 2011, 28, 683-692. [CrossRef]

28. Promeneur, D.; Kwon, T.H.; Yasui, M.; Kim, G.H.; Frokiaer, J.; Knepper, M.A.; Agre, P.; Nielsen, S. Regulation of AQP6 mRNA and protein expression in rats in response to altered acid-base or water balance. Am. J. Physiol. Ren. Physiol. 2000, 279, F1014-F1026. [CrossRef]

29. Rodriguez, A.; Catalan, V.; Gomez-Ambrosi, J.; Fruhbeck, G. Aquaglyceroporins serve as metabolic gateways in adiposity and insulin resistance control. Cell Cycle 2011, 10, 1548-1556. [CrossRef]

30. Tanaka, Y.; Watari, M.; Saito, T.; Morishita, Y.; Ishibashi, K. Enhanced Autophagy in Polycystic Kidneys of AQP11 Null Mice. Int. J. Mol. Sci. 2016, 17, 1993. [CrossRef]

31. Tanaka, A.; Nakamura, T.; Sato, E.; Node, K. Aquaporin-2 is a potential biomarker for tolvaptan efficacy in decompensated heart failure complicated by diabetic nephrotic syndrome. Int. J. Cardiol. 2016, 210, 1-3. [CrossRef]

32. Rini, B.I.; Campbell, S.C. Urinary Biomarkers for the Detection and Management of Localized Renal Cell Carcinoma. JAMA Oncol. 2015, 1, 212-213. [CrossRef]

33. Rossi, L.; Nicoletti, M.C.; Carmosino, M.; Mastrofrancesco, L.; Di Franco, A.; Indrio, F.; Lella, R.; Laviola, L.; Giorgino, F.; Svelto, M.; et al. Urinary Excretion of Kidney Aquaporins as Possible Diagnostic Biomarker of Diabetic Nephropathy. J. Diabetes Res. 2017, 2017. [CrossRef] [PubMed]

34. Bockenhauer, D.; Bichet, D.G. Pathophysiology, diagnosis and management of nephrogenic diabetes insipidus. Nat. Rev. Nephrol. 2015, 11, 576-588. [CrossRef] [PubMed] 
35. Kotnik, P.; Battelino, T.; Debeljak, M.; Podkrajsek, K.T.; Waldhauser, F.; Frokiaer, J.; Nielsen, S.; Krzisnik, C. Correlation between AVPR2 mutations and urinary AQP2 excretion in patients with nephrogenic diabetes insipidus. J. Pediatr. Endocrinol. Metab. 2007, 20, 483-489. [CrossRef]

36. Schernthaner-Reiter, M.H.; Stratakis, C.A.; Luger, A. Genetics of Diabetes Insipidus. Endocrinol. Metab. Clin. N. Am. 2017, 46, 305-334. [CrossRef]

37. Sands, J.M. Water, Water Everywhere: A New Cause and a New Treatment for Nephrogenic Diabetes Insipidus. J. Am. Soc. Nephrol. 2016, 27, 1872-1874. [CrossRef] [PubMed]

38. Yang, B.; Zhao, D.; Verkman, A.S. Hsp90 inhibitor partially corrects nephrogenic diabetes insipidus in a conditional knock-in mouse model of aquaporin-2 mutation. FASEB J. 2009, 23, 503-512. [CrossRef]

39. Yang, B.; Zhao, D.; Qian, L.; Verkman, A.S. Mouse model of inducible nephrogenic diabetes insipidus produced by floxed aquaporin-2 gene deletion. Am. J. Physiol. Ren. Physiol. 2006, 291, F465-F472. [CrossRef] [PubMed]

40. Yang, B.; Gillespie, A.; Carlson, E.J.; Epstein, C.J.; Verkman, A.S. Neonatal mortality in an aquaporin-2 knock-in mouse model of recessive nephrogenic diabetes insipidus. J. Biol. Chem. 2001, 276, 2775-2779. [CrossRef]

41. Lin, Y.; Zhang, T.; Feng, P.; Qiu, M.; Liu, Q.; Li, S.; Zheng, P.; Kong, Y.; Levi, M.; Li, C.; et al. Aliskiren increases aquaporin-2 expression and attenuates lithium-induced nephrogenic diabetes insipidus. Am. J. Physiol. Ren. Physiol. 2017, 313, F914-F925. [CrossRef]

42. Suzuki, T.; Seki, S.; Hiramoto, K.; Naganuma, E.; Kobayashi, E.H.; Yamaoka, A.; Baird, L.; Takahashi, N.; Sato, H.; Yamamoto, M. Hyperactivation of Nrf2 in early tubular development induces nephrogenic diabetes insipidus. Nat. Commun. 2017, 8, 14577. [CrossRef] [PubMed]

43. Khositseth, S.; Uawithya, P.; Somparn, P.; Charngkaew, K.; Thippamom, N.; Hoffert, J.D.; Saeed, F.; Michael, P.D.; Chen, S.H.; Fenton, R.A.; et al. Autophagic degradation of aquaporin-2 is an early event in hypokalemia-induced nephrogenic diabetes insipidus. Sci. Rep. 2015, 5, 18311. [CrossRef] [PubMed]

44. Khositseth, S.; Charngkaew, K.; Boonkrai, C.; Somparn, P.; Uawithya, P.; Chomanee, N.; Payne, D.M.; Fenton, R.A.; Pisitkun, T. Hypercalcemia induces targeted autophagic degradation of aquaporin-2 at the onset of nephrogenic diabetes insipidus. Kidney Int. 2017, 91, 1070-1087. [CrossRef]

45. Rieg, T.; Tang, T.; Murray, F.; Schroth, J.; Insel, P.A.; Fenton, R.A.; Hammond, H.K.; Vallon, V. Adenylate cyclase 6 determines cAMP formation and aquaporin-2 phosphorylation and trafficking in inner medulla. J. Am. Soc. Nephrol. 2010, 21, 2059-2068. [CrossRef] [PubMed]

46. Rao, R.; Patel, S.; Hao, C.; Woodgett, J.; Harris, R. GSK3beta mediates renal response to vasopressin by modulating adenylate cyclase activity. J. Am. Soc. Nephrol. 2010, 21, 428-437. [CrossRef]

47. Ando, F.; Mori, S.; Yui, N.; Morimoto, T.; Nomura, N.; Sohara, E.; Rai, T.; Sasaki, S.; Kondo, Y.; Kagechika, H.; et al. AKAPs-PKA disruptors increase AQP2 activity independently of vasopressin in a model of nephrogenic diabetes insipidus. Nat. Commun. 2018, 9, 1411. [CrossRef]

48. Bankir, L. Antidiuretic action of vasopressin: Quantitative aspects and interaction between V1a and V2 receptor-mediated effects. Cardiovasc. Res. 2001, 51, 372-390. [CrossRef]

49. Gao, M.; Cao, R.; Du, S.; Jia, X.; Zheng, S.; Huang, S.; Han, Q.; Liu, J.; Zhang, X.; Miao, Y.; et al. Disruption of prostaglandin E2 receptor EP4 impairs urinary concentration via decreasing aquaporin 2 in renal collecting ducts. Proc. Natl. Acad. Sci. USA 2015, 112, 8397-8402. [CrossRef]

50. Bonfrate, L.; Procino, G.; Wang, D.Q.; Svelto, M.; Portincasa, P. A novel therapeutic effect of statins on nephrogenic diabetes insipidus. J. Cell. Mol. Med. 2015, 19, 265-282. [CrossRef]

51. Hatem-Vaquero, M.; Griera, M.; Giermakowska, W.; Luengo, A.; Calleros, L.; Gonzalez, B.L.; Rodriguez-Puyol, D.; Rodriguez-Puyol, M.; De Frutos, S. Integrin linked kinase regulates the transcription of AQP2 by NFATC3. Biochim. Biophys. Acta Gene Regul. Mech. 2017, 1860, 922-935. [CrossRef] [PubMed]

52. Farrar, A. Acute Kidney Injury. Nurs Clin North Am. 2018, 53, 499-510. [CrossRef] [PubMed]

53. Asvapromtada, S.; Sonoda, H.; Kinouchi, M.; Oshikawa, S.; Takahashi, S.; Hoshino, Y.; Sinlapadeelerdkul, T.; Yokota-Ikeda, N.; Matsuzaki, T.; Ikeda, M. Characterization of urinary exosomal release of aquaporin-1 and -2 after renal ischemia-reperfusion in rats. Am. J. Physiol. Ren. Physiol. 2018, 314, F584-F601. [CrossRef] [PubMed]

54. Hussein, A.A.; El-Dken, Z.H.; Barakat, N.; Abol-Enein, H. Renal ischaemia/reperfusion injury: Possible role of aquaporins. Acta Physiol. 2012, 204, 308-316. [CrossRef] [PubMed] 
55. Wang, W.; Li, C.; Summer, S.N.; Falk, S.; Wang, W.; Ljubanovic, D.; Schrier, R.W. Role of AQP1 in endotoxemia-induced acute kidney injury. Am. J. Physiol. Ren. Physiol. 2008, 294, F1473-F1480. [CrossRef] [PubMed]

56. Lei, L.; Wang, W.; Jia, Y.; Su, L.; Zhou, H.; Verkman, A.S.; Yang, B. Aquaporin-3 deletion in mice results in renal collecting duct abnormalities and worsens ischemia-reperfusion injury. Biochim. Biophys. Acta Mol. Basis Dis. 2017, 1863, 1231-1241. [CrossRef] [PubMed]

57. MacManes, M.D. Severe acute dehydration in a desert rodent elicits a transcriptional response that effectively prevents kidney injury. Am. J. Physiol. Ren. Physiol. 2017, 313, F262-F272. [CrossRef]

58. Gao, J.; Gu, Z.; Li, M.; Xu, Y.; Gao, Y.; Wei, J.; Liang, B.; Na, Y. L-Carnitine Ameliorates the Decrease of Aquaporin 2 Levels in Rats with Cisplatin-Induced Kidney Injury. Nephron 2017, 135, 315-325. [CrossRef]

59. Suh, S.H.; Lee, K.E.; Kim, I.J.; Kim, O.; Kim, C.S.; Choi, J.S.; Choi, H.I.; Bae, E.H.; Ma, S.K.; Lee, J.U.; et al. Alpha-lipoic acid attenuates lipopolysaccharide-induced kidney injury. Clin. Exp. Nephrol. 2015, 19, 82-91. [CrossRef]

60. Kuper, C.; Fraek, M.L.; Muller, H.H.; Beck, F.X.; Neuhofer, W. Sepsis-induced urinary concentration defect is related to nitric oxide-dependent inactivation of TonEBP/NFAT5, which downregulates renal medullary solute transport proteins and aquaporin-2. Crit. Care Med. 2012, 40, 1887-1895. [CrossRef]

61. Hocherl, K.; Schmidt, C.; Kurt, B.; Bucher, M. Inhibition of NF-kappaB ameliorates sepsis-induced downregulation of aquaporin-2/V2 receptor expression and acute renal failure in vivo. Am. J. Physiol. Ren. Physiol. 2010, 298, F196-F204. [CrossRef] [PubMed]

62. Ho, K.M.; Li, A.Z.; Yiu, M.K.; Lee, K.C.; Lui, V.C.; Fung, P.C.; Yiu, T.F.; Tam, P.K. Altered expression of aquaporin-2 in human explants with chronic renal allograft dysfunction. BJU Int. 2005, 95, 1104-1108. [CrossRef] [PubMed]

63. Chen, B.; Zang, C.S.; Zhang, J.Z.; Wang, W.G.; Wang, J.G.; Zhou, H.L.; Fu, Y.W. The changes of aquaporin 2 in the graft of acute rejection rat renal transplantation model. Transpl. Proc. 2010, 42, 1884-1887. [CrossRef] [PubMed]

64. Atochina-Vasserman, E.N.; Biktasova, A.; Abramova, E.; Cheng, D.S.; Polosukhin, V.V.; Tanjore, H.; Takahashi, S.; Sonoda, H.; Foye, L.; Venkov, C.; et al. Aquaporin 11 insufficiency modulates kidney susceptibility to oxidative stress. Am. J. Physiol. Ren. Physiol. 2013, 304, F1295-F1307. [CrossRef] [PubMed]

65. Choma, D.P.; Vanacore, R.; Naylor, H.; Zimmerman, I.A.; Pavlichenko, A.; Pavlichenko, A.; Foye, L.; Carbone, D.P.; Harris, R.C.; Dikov, M.M.; et al. Aquaporin 11 variant associates with kidney disease in type 2 diabetic patients. Am. J. Physiol. Ren. Physiol. 2016, 310, F416-F425. [CrossRef]

66. Afkarian, M.; Zelnick, L.R.; Hall, Y.N.; Heagerty, P.J.; Tuttle, K.; Weiss, N.S.; de Boer, I.H. Clinical Manifestations of Kidney Disease Among US Adults with Diabetes, 1988-2014. JAMA 2016, 316, 602-610. [CrossRef]

67. Tang, S.C.; Yiu, W.H.; Lin, M.; Lai, K.N. Diabetic nephropathy and proximal tubular damage. J. Ren. Nutr. 2015, 25, 230-233. [CrossRef]

68. Wu, H.; Chen, L.; Zhang, X.; Zhou, Q.; Li, J.M.; Berger, S.; Borok, Z.; Zhou, B.; Xiao, Z.; Yin, H.; et al. Aqp5 is a new transcriptional target of Dot1a and a regulator of Aqp2. PLoS ONE 2013, 8, e53342. [CrossRef]

69. Han, B.; Wu, X.; Huang, P.P.; Zhu, F.X.; Liu, S. Aquaporin 11 rs2276415 variant and progression of chronic kidney disease. Nephrol. Dial. Transpl. 2018. [CrossRef]

70. Lu, Y.; Chen, L.; Zhao, B.; Xiao, Z.; Meng, T.; Zhou, Q.; Zhang, W. Urine AQP5 is a potential novel biomarker of diabetic nephropathy. J. Diabetes Complicat. 2016, 30, 819-825. [CrossRef]

71. Harris, P.C.; Torres, V.E. Genetic mechanisms and signaling pathways in autosomal dominant polycystic kidney disease. J. Clin. Investig. 2014, 124, 2315-2324. [CrossRef]

72. Magistroni, R. Tolvaptan: Clinical Evidence for Slowing the Progression of Autosomal Dominant Polycystic Kidney Disease. G Tec Nefrol. Dial. 2017, 29, 80-84. [CrossRef] [PubMed]

73. Padovano, V.; Podrini, C.; Boletta, A.; Caplan, M.J. Metabolism and mitochondria in polycystic kidney disease research and therapy. Nat. Rev. Nephrol. 2018, 14, 678-687. [CrossRef] [PubMed]

74. Raman, A.; Reif, G.A.; Dai, Y.; Khanna, A.; Li, X.; Astleford, L.; Parnell, S.C.; Calvet, J.P.; Wallace, D.P. Integrin-Linked Kinase Signaling Promotes Cyst Growth and Fibrosis in Polycystic Kidney Disease. J. Am. Soc. Nephrol. 2017, 28, 2708-2719. [CrossRef] [PubMed]

75. Ong, A. Polycystic kidney disease: Tolvaptan slows disease progression in late-stage ADPKD. Nat. Rev. Nephrol. 2018. [CrossRef] [PubMed] 
76. Ciolek, J.; Reinfrank, H.; Quinton, L.; Viengchareun, S.; Stura, E.A.; Vera, L.; Sigismeau, S.; Mouillac, B.; Orcel, H.; Peigneur, S.; et al. Green mamba peptide targets type-2 vasopressin receptor against polycystic kidney disease. Proc. Natl. Acad. Sci. USA 2017, 114, 7154-7159. [CrossRef]

77. Lanktree, M.B.; Chapman, A.B. New treatment paradigms for ADPKD: Moving towards precision medicine. Nat. Rev. Nephrol. 2017, 13, 750-768. [CrossRef] [PubMed]

78. Devuyst, O.; Burrow, C.R.; Smith, B.L.; Agre, P.; Knepper, M.A.; Wilson, P.D. Expression of aquaporins-1 and -2 during nephrogenesis and in autosomal dominant polycystic kidney disease. Am. J. Physiol. 1996, 271, F169-F183. [CrossRef]

79. Wang, W.; Li, F.; Sun, Y.; Lei, L.; Zhou, H.; Lei, T.; Xia, Y.; Verkman, A.S.; Yang, B. Aquaporin-1 retards renal cyst development in polycystic kidney disease by inhibition of Wnt signaling. FASEB J. 2015, 29, 1551-1563. [CrossRef]

80. Aboudehen, K.; Noureddine, L.; Cobo-Stark, P.; Avdulov, S.; Farahani, S.; Gearhart, M.D.; Bichet, D.G.; Pontoglio, M.; Patel, V.; Igarashi, P. Hepatocyte Nuclear Factor-1beta Regulates Urinary Concentration and Response to Hypertonicity. J. Am. Soc. Nephrol. 2017, 28, 2887-2900. [CrossRef]

81. Noitem, R.; Yuajit, C.; Soodvilai, S.; Muanprasat, C.; Chatsudthipong, V. Steviol slows renal cyst growth by reducing AQP2 expression and promoting AQP2 degradation. Biomed. Pharm. 2018, 101, 754-762. [CrossRef] [PubMed]

82. Saito, T.; Tanaka, Y.; Morishita, Y.; Ishibashi, K. Proteomic analysis of AQP11-null kidney: Proximal tubular type polycystic kidney disease. Biochem. Biophys. Rep. 2018, 13, 17-21. [CrossRef]

83. Inoue, Y.; Sohara, E.; Kobayashi, K.; Chiga, M.; Rai, T.; Ishibashi, K.; Horie, S.; Su, X.; Zhou, J.; Sasaki, S.; et al. Aberrant glycosylation and localization of polycystin-1 cause polycystic kidney in an AQP11 knockout model. J. Am. Soc. Nephrol. 2014, 25, 2789-2799. [CrossRef] [PubMed]

84. Rini, B.I.; Campbell, S.C.; Escudier, B. Renal cell carcinoma. Lancet 2009, 373, 1119-1132. [CrossRef]

85. Wang, X.; Ren, Y.; Zhuang, H.; Meng, X.; Huang, S.; Li, Y.; Hehir, M.; Wang, P. Decrease of phosphorylated proto-oncogene CREB at Ser 133 site inhibits growth and metastatic activity of renal cell cancer. Expert Opin. Ther. Targets 2015, 19, 985-995.

86. Morrissey, J.J.; Mellnick, V.M.; Luo, J.; Siegel, M.J.; Figenshau, R.S.; Bhayani, S.; Kharasch, E.D. Evaluation of Urine Aquaporin-1 and Perilipin-2 Concentrations as Biomarkers to Screen for Renal Cell Carcinoma: A Prospective Cohort Study. JAMA Oncol. 2015, 1, 204-212. [CrossRef] [PubMed]

87. Song, J.B.; Morrissey, J.J.; Mobley, J.M.; Figenshau, K.G.; Vetter, J.M.; Bhayani, S.B.; Kharasch, E.D.; Figenshau, R.S. Urinary aquaporin 1 and perilipin 2: Can these novel markers accurately characterize small renal masses and help guide patient management? Int. J. Urol. 2018. [CrossRef]

88. Morrissey, J.J.; Mobley, J.; Figenshau, R.S.; Vetter, J.; Bhayani, S.; Kharasch, E.D. Urine aquaporin 1 and perilipin 2 differentiate renal carcinomas from other imaged renal masses and bladder and prostate cancer. Mayo Clin. Proc. 2015, 90, 35-42.

89. Seeger-Nukpezah, T.; Geynisman, D.M.; Nikonova, A.S.; Benzing, T.; Golemis, E.A. The hallmarks of cancer: Relevance to the pathogenesis of polycystic kidney disease. Nat. Rev. Nephrol. 2015, 11, 515-534. [CrossRef]

90. Nastase, M.V.; Zeng-Brouwers, J.; Wygrecka, M.; Schaefer, L. Targeting renal fibrosis: Mechanisms and drug delivery systems. Adv. Drug Deliv. Rev. 2018, 129, 295-307. [CrossRef]

91. Efstratiadis, G.; Divani, M.; Katsioulis, E.; Vergoulas, G. Renal fibrosis. Hippokratia 2009, 13, 224-229. [PubMed]

92. Lovisa, S.; LeBleu, V.S.; Tampe, B.; Sugimoto, H.; Vadnagara, K.; Carstens, J.L.; Wu, C.C.; Hagos, Y.; Burckhardt, B.C.; Pentcheva-Hoang, T.; et al. Epithelial-to-mesenchymal transition induces cell cycle arrest and parenchymal damage in renal fibrosis. Nat. Med. 2015, 21, 998-1009. [CrossRef] [PubMed]

93. Li, J.; Zhang, M.; Mao, Y.; Li, Y.; Zhang, X.; Peng, X.; Yu, F. The potential role of aquaporin 1 on aristolochic acid I induced epithelial mesenchymal transition on HK-2 cells. J. Cell. Physiol. 2018, 233, 4919-4925. [CrossRef] [PubMed]

94. Wang, W.; Luo, R.; Lin, Y.; Wang, F.; Zheng, P.; Levi, M.; Yang, T.; Li, C. Aliskiren restores renal AQP2 expression during unilateral ureteral obstruction by inhibiting the inflammasome. Am. J. Physiol. Ren. Physiol. 2015, 308, F910-F922. [CrossRef] [PubMed]

95. Liu, N.; Zhang, Y.; Su, H.; Wang, J.; Liu, Z.; Kong, J. Effects of cholecalciferol cholesterol emulsion on renal fibrosis and aquaporin 2 and 4 in mice with unilateral ureteral obstruction. Biomed. Pharm. 2018, 102, 633-638. [CrossRef] [PubMed] 
96. Landegren, N.; Pourmousa, L.M.; Skov, J.; Hallgren, A.; Eriksson, D.; Lisberg, T.T.; MacAulay, N.; Hagforsen, E.; Raisanen-Sokolowski, A.; Saha, H.; et al. Autoantibodies Targeting a Collecting Duct-Specific Water Channel in Tubulointerstitial Nephritis. J. Am. Soc. Nephrol. 2016, 27, 3220-3228. [CrossRef]

97. Rocchetti, M.T.; Tamma, G.; Lasorsa, D.; Suriano, I.V.; D'Apollo, A.; Papale, M.; Mastrofrancesco, L.; Grandaliano, G.; Svelto, M.; Valenti, G.; et al. Altered urinary excretion of aquaporin 2 in IgA nephropathy. Eur. J. Endocrinol. 2011, 165, 657-664. [CrossRef]

98. Rodionova, E.A.; Kuznetsova, A.A.; Shakhmatova, E.I.; Prutskova, N.; Nielsen, S.; Holtback, U.; Natochin, Y.; Zelenina, M. Urinary aquaporin-2 in children with acute pyelonephritis. Pediatr. Nephrol. 2006, 21, 361-367. [CrossRef]

99. Ampawong, S.; Klincomhum, A.; Likitsuntonwong, W.; Singha, O.; Ketjareon, T.; Panavechkijkul, Y.; Zaw, K.M.; Kengkoom, K. Expression of aquaporin-1, -2 and -4 in mice with a spontaneous mutation leading to hydronephrosis. J. Comp. Pathol. 2012, 146, 332-337. [CrossRef]

100. Verkman, A.S.; Anderson, M.O.; Papadopoulos, M.C. Aquaporins: Important but elusive drug targets. Nat. Rev. Drug Discov. 2014, 13, 259-277. [CrossRef]

(C) 2019 by the authors. Licensee MDPI, Basel, Switzerland. This article is an open access article distributed under the terms and conditions of the Creative Commons Attribution (CC BY) license (http://creativecommons.org/licenses/by/4.0/). 